\title{
ENOTURISMO E TERRITÓRIO: O CASO DO VALE DOS VINHEDOS (RS/BRASIL)
}

ENOTOURISM AND TERRITORY: THE CASE OF VALE DOS VINHEDOS (RS / BRAZIL) ENOTURISMO Y TERRITORIO: ESTUDIO DE CASO DEL VALLE DE LOS VIÑNEDOS (RS/BRASIL)

Adilene Alvares Mattia Universidade do Vale do Itajaí-UNIVALI, Balneário Camboriú, Brasil Doutora em Desenvolvimento Regional- UNISC amattia@univali.br

Janaina Macke

Universidade de Caxias do Sul- UCS IMED Business School, Faculdade Meridional, Passo Fundo, Brasil Pós-doutorado na Université Joseph Fourier (França) jmacke@gmail.com

\section{João Alberto Rubim Sarate}

IMED Business School, Faculdade Meridional, Passo Fundo, Brasil

Doutor em Administração (UFRGS) joao.sarate@imed.edu.br

Submetido em: 06/09/2016 Aprovado em:31/10/2016

RESUMO: Três elementos do desenvolvimento local se destacam a partir do turismo: a sociedade, o ambiente e a economia. Estes elementos são integrados e se reforçam mutuamente, em contextos nos quais a diversidade social e cultural e a diferenciação produtiva são utilizadas como recursos potenciadores de transformações e de desenvolvimento local. A região do Vale dos Vinhedos (Brasil) transformou-se no mais importante parque vitícola e enológico do País, além de produtora de vinhos destaca-se como 
ISSN: 1983-7151

destino enoturístico. Este estudo caracteriza-se como um estudo de caso exploratório-descritivo, de caráter qualitativo, constitui-se em uma análise exploratória feita à luz do conceito de desenvolvimento territorial. Desta análise, foram formuladas novas questões de pesquisa que visam ao atendimento das novas demandas que vêm desafiando a região. Buscou-se analisar o desenvolvimento territorial do Vale dos Vinhedos, vinculando os conceitos de território e de recursos territoriais ao modelo de ciclo de vida do turismo. Podemos verificar a partir da análise do ciclo de vida, que o Vale dos Vinhedos está no estágio de "Desenvolvimento", o que inicia uma tendência de diminuição da participação da comunidade local no planejamento e tomada de decisão em relação ao processo de desenvolvimento turístico.

PALAVRAS-CHAVE: Enoturismo, Território, ciclo de vida, Vale dos Vinhedos RS/Brasil.

ABSTRACT: Three elements of local development are highlighted by tourism activity: the society, the environment and the economy, that are integrated and reinforce themselves mutually, on the context that the social and cultural diversity and the productive differentiation must be used as potential transformational resources and of local development. The Vale dos Vinhedos (Brazil) region has become the most important wine and oenology park in the country, that beyond producing wines also manifests itself as a oenotouristic destine. This study is characterized as an exploratory-descriptive, of quali-quantitative character, and constitutes a preliminar and exploratory analysis made under the light of a territorial development concept. From this analysis new research questions have been formulated that aim to further the territorial development of Vale dos Vinhedos, attaching the concepts of territory and territorial resources to the tourism life cycle model. We are able to verify, from the life cycle analysis, that the Vale dos Vinhedos is on the "Development" stage, which indicates a tendency of diminishing participation of the local community on the planning and decision making of the touristic development process.

KEY WORDS: Oenotouristic, Territory, life cycle, Vale dos Vinhedos RS/Brasil.

RESUMEN: Se destacan tres elementos del desarrollo local a partir del turismo: la sociedad, el medio ambiente y la economía, que son integrados y se refuerzan mutuamente en el contexto en que la diversidad social, cultural y las diferencias productivas deben ser analizadas como recursos potenciadores de transformación y de desarrollo local. La Región del Valle de los Viñedos (Brasil) se transformó en el más importante parque vitivinícola y ecológico del país, además, de productora de vinos se destaca como destino enoturístico. Este estudio se caracteriza como estudio de caso exploratorio-descriptivo, carácter cualitativo-cuantitativo, constituyéndose en un análisis preliminar y exploratorio realizado a la luz el concepto de desarrollo territorial. De este análisis fueron formuladas nuevas preguntas de investigación orientadas a satisfacer las nuevas demandas que han desafiado a la región. Se trató de analizar el desarrollo territorial del Valle de los Viñedos, vinculando los conceptos de territorio y de recursos territoriales al modelo de ciclo de vida del turismo. Podemos verificar a partir del análisis del ciclo de vida, que el Valle de los Viñedos está en la etapa de "Desarrollo" lo cual se inicia una tendencia a la disminución de la participación de la comunidad local en la planificación y toma de decisiones en relación a los procesos de desarrollo turístico.

PALABRAS CLAVE: Enoturismo, Territorio, ciclo de vida, Vale dos Vinhedos RS/Brasil .

INTRODUÇÃO 
pode ser identificado como área delimitada: município, microrregião etc. Outra é o espaço abstrato das relações sociais e indica movimento e interação dos grupos sociais que se articulam ou se opõem em torno de interesses comuns (Fischer, 2002). A ideia de movimento e interação é observada na medida em que o território deve levar em conta a interdependência da natureza com o seu uso, que inclui a ação humana, isto é, o trabalho e a política (Santos, 1999).

Três elementos do desenvolvimento local se destacam a partir do turismo: a sociedade, o ambiente e a economia. Estes elementos são integrados e se reforçam mutuamente, em contextos nos quais a diversidade social e cultural e a diferenciação produtiva são utilizadas como recursos potenciadores de transformações e de desenvolvimento local.

A partir do entendimento do território como um projeto socioeconômico e político geograficamente situado, há um propósito para sua existência e o grupo social que lá se encontra dispõe de recursos que podem ser utilizados, manejados, no sentido de desenvolver o território. Neste sentido, Gumuchian e Pecqueur (2007) ampliam o entendimento de recursos territoriais, afirmando que estes vão além dos simples recursos materiais. Segundo os autores, devem ser considerados também os elementos imateriais, tais como os saberes individuais e coletivos historicamente construídos pela sociedade local. Desta forma, a soma de tais recursos e sua forma de utilização contribui para o estabelecimento de processos "únicos" de territorialização (Sarate, 2014).

O turismo possui algumas características que podem garantir este caráter único e que o diferenciam de outras atividades produtivas: é um produto que só pode ser consumido in loco; estimula o desenvolvimento de outras atividades econômicas (entretenimento, comércio, transportes, meios de hospedagem, agências de viagens, artesanato, serviços de apoio); estimula o desenvolvimento da infraestrutura (estradas, aeroportos, saneamento, energia etc.); depende da sustentabilidade cultural e ambiental e tem forte efeito indutor na geração de renda e emprego local.

Neste sentido, cabe analisar o ciclo de vida dos destinos turísticos, como forma de identificar lacunas, entraves e pontos de alavancagem ao desenvolvimento territorial. Desde a década de 1980, os pesquisadores 
têm utilizado o modelo do Tourism Area Life Cycle (TALC), o qual prevê seis estágios: exploração, desenvolvimento, consolidação, estagnação e renovação (ou declínio) (BUTLER, 1980).

A análise do ciclo de vida tem sido considerada um dos métodos mais acurados para análise do desenvolvimento de destinos turísticos (Lagiewski, 2006; Haywood, 2006). O modelo TALC fornece subsídios para a revisão do pressuposto, tão presente na gestão do turismo, de que áreas turísticas sempre se manterão como áreas turísticas quando na verdade, estão sujeitas à dinamicidade e a processos de deterioração.

A região do Vale dos Vinhedos (Brasil) transformou-se no mais importante parque vitícola e enológico do País, pela elaboração de vinhos finos de qualidade e pelo reconhecimento por meio de premiações. Atualmente, através de novas técnicas vitivinícolas, com o propósito de aprimoramento da produção, a região vive um cenário de transformação para fortalecimento da conquista do reconhecimento internacional, como produtora de vinhos e como destino enoturístico.

A importância socioeconômica da indústria da uva e do vinho no Brasil é considerável e crescente. Como atividade agrícola a cadeia produtiva emprega mais de 20 mil famílias, não apenas no Rio Grande do Sul (RS), estado de maior produção, mas também nos outros 11 Estados brasileiros. No Rio Grande do Sul, a produção de vinhos e derivados da uva representa $90 \%$ do total produzido no Brasil, no ano de 2015 teve uma produção de 442,50 milhões de litros (IBRAVIN, 2015).

Com o intuito de verificar as abordagens dos diferentes aspectos e dimensões sobre o Vale dos Vinhedos, destaca-se alguns estudos: no campo das redes de cooperação, clusters e competitividade (Fensterseifer \& Wilk, 2005; Gollo, 2006; Macke et al., 2013; Mattia et al., 2015); na vinculação com desenvolvimento territorial e enoturismo (Vander, 2012; Zanini \& Rocha, 2010; Padula, 2009) e nos estudos do campo da geografia, denominação de procedência e qualidade dos vinhos (Falcade, 2004; Niederlle, 2011; Blume, 2009; Taffarel, 2013).

Com o destaque que a região vem recebendo, este estudo tem como objetivo analisar o desenvolvimento territorial do Vale dos Vinhedos, vinculando os conceitos de território e de recursos territoriais ao modelo de ciclo de vida do 
turismo e em uma análise preliminar e exploratória. A partir desta análise, serão formuladas novas questões de pesquisa que visem a atender novas demandam que vêm desafiando a região.

Em termos estruturais, além desta introdução, são apresentadas abordagens teóricas, sobre desenvolvimento, recursos territoriais e espaços enoturísticos. $\mathrm{Na}$ seção seguinte, a metodologia e as informações contextuais sobre a região. Finalmente, a análise dos resultados, seguida das considerações finais do estudo.

\section{DESENVOLVIMENTO E RECURSOS TERRITORIAIS: O TERRITÓRIO COMO ESPAÇO DE DIFERENCIAÇÃO}

A presente seção visa a recuperar um grupo de conceitos da ciência geográfica ancorando-os aos propósitos analíticos deste estudo, ou seja, o papel de uma região como ambiente indutor de desenvolvimento territorial, a partir da atividade turística.

O território tornou-se um conceito empregado por diversas ciências que se ocupam dos processos de produção do espaço. Conforme Santos (2002, p. 9), o território é o lugar em que "desembocam todas as ações, todas as paixões, todos os poderes, todas as forças, todas as fraquezas, isto é, onde a história do homem se realiza a partir de manifestações de sua existência". As relações e classes sociais produzem diferentes territórios e espaços que as reproduzem em constantes conflitos.

As disputas territoriais não se limitam ao espaço econômico. Como o território, é uma totalidade multidimensional, isto é, as dimensões que a compõem, as disputas territoriais, ocorrem também na dimensão política, teórica e ideológica, o que nos possibilita entender os territórios materiais e imateriais. Além disso, a totalidade é um paradigma que pauta sua interpretação de funcionamento do mundo; é elemento essencial para conhecimento e análise da realidade.

O território é sempre, e concomitantemente, apropriação (num sentido mais simbólico) e domínio (num enfoque mais concreto, político-econômico) de um espaço socialmente partilhado e não simplesmente construído. (Souza, 2006). 
Num primeiro momento, pode-se inferir que o sentido simbólico de território advém da identidade cultural e pode ser influenciado por ela, que faz dele um referencial considerável para a coesão dos grupos sociais. A dimensão simbólica atribuída ao território promove o surgimento das identidades territoriais e a identificação que determinados grupos sociais desenvolvem com seus espaços vividos.

Santos (1988) ressalta que o território é subjacente, composto de variáveis, tais como a produção, as firmas, as instituições, os fluxos, os fixos, relações de trabalho etc., e que essas variáveis formam a configuração territorial "formada pela constelação de recursos naturais, lagos, rios, planícies, montanhas, florestas e também recursos criados: estradas de ferro e de rodagem, condutos de toda ordem, barragens, cidades, o que for" (Santos, 1988, p. 75).

Desta forma, Saquet (2010) afirma que o problema que atualmente se apresenta, é como a diversidade de recursos territoriais - recursos ecológicos, humanos, cognitivos, simbólicos, culturais que cada território pode oferecer pode ser potencializada, conservada e reproduzida em um mundo no qual a produção de valor é controlada por um sistema econômico-financeiro global, que tem como única força a acumulação capitalista e, como resultados, a alteração da biosfera, redução da biodiversidade e da diversidade cultural (Saquet, 2010, p.10)

Neste sentido é preciso ampliar a compreensão do território. Di Méo (1998) sugere quatro dimensões como essenciais para compreensão do conceito de território a partir da experiência social. São elas:

a) Dimensão coletiva - que descreve a inserção de um indivíduo num grupo social de referência. A experiência concreta do espaço social a partir dos "itinerários" de cada indivíduo é que articula o relacionamento com os outros, permitindo assim a construção dos sentidos de pertencimento e de identidade coletiva;

b) Dimensão política - que traduz o modo de demarcação e controle do espaço, garantindo a sua especificidade e sua manutenção e a reprodução dos grupos sociais que o ocupam. Essa dimensão ilustra a natureza intencional e voluntária da criação do território; 
c) Dimensão simbólica - que é composta por valores patrimoniais que reforçam o sentimento de pertencimento, mas que ao mesmo tempo estabelece uma distância enorme em relação ao exterior do território;

d) Dimensão histórica - que existe porque o território é função do transcurso do tempo, da repetição silenciosa, da maturação lenta, do trabalho do imaginário social sobre os padrões e as normas que definem o território. A história é matéria-prima para a construção simbólica do território e detém a atenção da maior parte dos atores sociais que nele vivem.

Nesta perspectiva, o território é uma "construção" humana a partir de um espaço que se constitui na "fonte" de constituição do território, razão pela qual, muitas vezes, encontramos a expressão espaço-territorial. Portanto, o indivíduo tem um papel formador, como ator dessa construção, desenvolvendo, através de intencionalidades e comportamentos, uma apropriação social do espaço, isto é, o território. Assim, forma-se um construto não palpável, coordenador da formação do espaço. Um território, assim entendido, se dá a partir de aspectos de formação social, como os aspectos socioeconômicos e político-ideológicos (Raffestin, 1993; Eduardo, 2006; Saquet, 2009).

O conceito de território pode ser também entendido como o resultado de projetos coletivos ligados à construção de recursos específicos através da diferenciação dos seus produtos e serviços (Mollard, 2001). Entende-se assim a lógica da economia territorial utilizando-se o conceito de multifuncionalidade (diversidade de recursos e savoir-faire locais) para justificar a estratégia de desenvolvimento territorial. O território pode ser definido ainda como a ação conjunta entre os atores sociais e agentes econômicos (Sarate, 2014).

Assim, o território não é apenas um simples receptáculo de agentes econômicos interessados em tirar algum proveito momentâneo. Pelo contrário, o território tem uma lógica própria não somente ligada a sua capacidade produtiva, mas também à capacidade de desenvolver-se e apoderar-se das externalidades positivas e fazê-las render, tornando-se assim, um agente inovador. O território poderá, assim, desempenhar um papel incitador e regulador de interesses múltiplos e divergentes, graças às instituições que souber reunir, tornando- 
se, agente econômico do seu próprio desenvolvimento (Azaïs, 2004). Neste sentido, a abordagem mesoeconômica proposta pela economia do território serve também como alternativa aos modelos de desenvolvimento: (i) top-down no qual o território é submetido a uma mundialização esmagadora ou seria apenas produto de agentes institucionais de promoção, ou ainda; (ii) bottomup, ou seja, uma expressão gloriosa de uma versão localista de desenvolvimento econômico (Azaïs, 2004).

Portanto, turismo só promoverá o desenvolvimento econômico e social, quando estiver comprometido com a conservação do patrimônio natural e cultural, ou seja, sua sustentabilidade depende do equilíbrio entre exploração e preservação (Oliveira, 2005).

\section{TERRITÓRIOS E ESPAÇOS ENOTURÍSTICOS}

Na perspectiva do processo de organização do espaço, o homem determinou várias práticas por meio das quais são criadas, mantidas, desfeitas e refeitas as formas e interações espaciais. Correa (1986, p. 35-36) denominou de práticas espaciais o "conjunto de ações espacialmente localizadas que impactam diretamente sobre o espaço". Segundo o autor, as práticas espaciais são as seguintes: seletividade espacial, fragmentação - remembramento espacial, antecipação espacial, marginalização espacial e reprodução da região produtora. Estas práticas espaciais não são mutuamente excludentes, podendo ocorrer combinadas ou com caráter complementar.

Neste sentido, Urry (1999) verifica uma relação intrínseca entre turismo e território, proposta a partir da turistificação dos territórios e de seletividades espaciais que se adaptam em novas funções nesse processo de transformação espacial.

há diferentes tipos de territorialidade que se confrontam nos lugares turísticos: a territorialidade sedentária dos que aí vivem frequentemente, e a territorialidade nômade dos que só passam, mas que não tem menos necessidade de se apropriar, mesmo fugidiamente, dos territórios que frequentam. Um bom número de conflitos nos lugares turísticos são oriundos das diferenças de territorialidade (1999, p. 64). 
Neste estudo destaca-se a utilização do território como uma categoria de análise reveladora da dinâmica social que esses grupos, distritos industriais, arranjos produtivos locais, cluster e enoturismo imprimem nos espaços demarcados pelo território do Vale dos Vinhedos, por exemplo. Ancorando-se em suas práticas espaciais, como o que Correa (1986) chamou de seletividade espacial - a escolha de um lugar que apresente atributos de interesse com os projetos estabelecidos.

O enoturismo é a junção de eno e turismo, sendo que eno deriva do grego oînos cujo significado é o vinho. Para Hall et al (2000, p.3), "o enoturismo é a atividade de visitar vinhedos, vinícolas, festivais do vinho e exposição de uva com degustação e vivenciar na prática as características de uma região de uva e vinho".

Neste sentido, pode-se definir o enoturismo como um segmento do fenômeno turismo, por meio do deslocamento de pessoas, cuja motivação esteja relacionada ao mundo da uva e vinho, bem como a apreciação das tradições, gastronomia, das paisagens e tipicidades das regiões produtoras. (Falcade, 2001; Valduga, 2012).

Neste sentido, para análise da evolução das indústrias, o ciclo de vida dos produtos é, na atualidade, um conceito disseminado, tanto ao nível do marketing como do posicionamento estratégico. Segundo Kotler (2006), para que um produto possua um ciclo de vida faz-se necessário atender alguns fatores, tais como: os produtos têm vida limitada; as vendas dos produtos passam por fases distintas; os lucros sobem ou descem nos diferentes estágios do ciclo de vida do produto; os produtos precisam de diferentes estratégias de produção, marketing, recursos humanos, financeira de acordo com cada estágio do seu ciclo de vida.

Kotler (2006) utiliza para ciclo de vida do produto (CPV) é dividida em quatro estágios os quais são conhecidos como: Introdução, Crescimento, Maturidade e Declínio. O autor ressalta que nem todos os produtos passam por todos os estágios de ciclo de vida. Isso se dá, pois alguns produtos morrem antes de chegar à maturidade ou até mesmo no primeiro estágio por erros de estratégia ou posicionamento de mercado. 
Como em todas as atividades econômicas também no turismo os produtos evoluem por fases. Pode-se aplicar conforme Choy (1992) o conceito do ciclo de vida a vários níveis, tais como: turismo em geral, produto turístico e destino turístico.

Com base no comportamento do turismo, Butler (1980) criou um modelo de ciclo de vida de destinações turísticas com base no conceito desenvolvido pelo marketing de produtos, e aplicou-o para estudar o crescimento e o declínio dos equipamentos turísticos e das regiões nas quais estes se localizam. Segundo o modelo elaborado pelo autor, um produto turístico compreende as seguintes fases: exploração, investimento, desenvolvimento, consolidação, estagnação e declínio ou rejuvenescimento e apresenta uma sucessão de estágios característicos de evolução.

Na fase de Exploração, o autor sugere que um destino é descoberto por alguns visitantes atraídos por uma oferta de recursos de infraestrutura como acomodações, facilidades de acesso e o uso da publicidade que no início se dá por meio do boca-a-boca. Os visitantes virão em pequenos números, inicialmente, com probabilidade de terem bastante contato com a comunidade local, usando a estrutura local. Como as instalações são fornecidas a percepção cresce e o número de visitantes irá aumentar. A motivação do turista se dá pelos aspectos naturais do local; trata-se da fase da descoberta.

No que diz respeito à fase de Envolvimento, geralmente o destino se apresenta sem uma estrutura voltada para o turista e seus recursos culturais e naturais encontram-se muito bem preservados, e em certo ponto inicia-se o "envolvimento" da comunidade oferecendo serviços especialmente ou até exclusivamente para turistas.

A fase do Desenvolvimento é marcada por áreas de mercado para turismo bem definidas, e com sua evolução há a tendência de diminuição da participação da comunidade local.

Na fase de Consolidação começa a diminuição na taxa de crescimento do número de turistas, ainda que esse o número continue a crescer. Grande parte da atividade econômica da área está vinculada ao turismo e o fluxo intenso de 
turistas tende a começar a criar desconforto por parte dos autóctones. Quando a fase de Estagnação é atingida o número máximo de visitantes é alcançado e apesar de possuir uma imagem bem estabelecida o destino não está mais na moda. Após esta fase o destino tende a entrar em "declínio" no número de turistas, com mudanças em parte das atividades e propriedades que deixam de ser voltadas ao turismo. O autor ainda prevê a fase de Rejuvenescimento, ainda que ele mesmo afirme que esse estágio, muito provavelmente, nunca será alcançado.

Para Faria e Carneiro (2001), quando o produto turístico é um produto natural, cabe ao planejador buscar novos mercados, uma vez que a modificação do produto torna-se inviável. A fim de manter o nível de ocupação dos equipamentos, os preços baixam e passam a atrair uma demanda de menor poder aquisitivo. A localidade pode passar por desgaste econômico, social e ambiental (Ruschmann, 1997).

Os fatores de saturação da área podem ser identificados por fatores ambientais (por exemplo, escassez da terra, qualidade de água, qualidade do ar), da planta física (por exemplo, transporte, acomodação, outros serviços), ou de fatores sociais (por exemplo, aglomeração e ressentimento pela população local) (Butler, 1980).

\section{METODOLOGIA}

No que diz respeito ao método, esta pesquisa possui caráter exploratóriodescritivo, uma vez que busca conhecer um relacionamento pouco explorado entre os temas. Dessa forma, é utilizado o método de estudo de caso, o qual está focado em eventos contemporâneos e responde satisfatoriamente a situações de pesquisa nas quais a fronteira entre fenômeno e contexto não é aparentemente clara (Yin, 1994). Além disso, é preciso destacar que o método de estudo de caso permite desenvolver novas teorias e ferramentas conceituais, como é o caso deste estudo (Eisenhardt, 1998).

Para Lakatos e Marconi (2008), o delineamento da pesquisa pode ser classificado por seu método ou natureza, pelos níveis de pesquisa /estudo e 
pela estratégia. Segundo os autores a pesquisa pode ser considerada qualitativa de nível exploratório, quando suas estratégias forem baseadas em estudos de caso, pesquisa bibliográfica, pesquisa documental, pesquisa experimental, pesquisa de ação, enquete estudo qualitativo genérico.

Este estudo constitui-se em uma análise exploratória feita a partir da experiência de dois projetos de pesquisa: "Território, recursos estratégicos, criação de valor e vantagem competitiva:" e "Capital Social e Territórios". Desta análise, serão formuladas novas questões de pesquisa que visem atender a novas demandam que vem desafiando a região.

\section{ENOTURISMO NO VALE DOS VINHEDOS (RS/BRASIL)}

Localizado na Região Sul do Brasil, mais especificamente na Serra Gaúcha, o Vale dos Vinhedos tem uma área total de $81 \mathrm{~km}^{2}$, possui altitude média de 740 metros e abrange parte de três municípios; Bento Gonçalves (nordeste), Monte Belo do Sul (noroeste) e Garibaldi (sul). Segundo Matheus e Silva (2008, p. 62) "a região é marcada por encostas cobertas de parreiras e pequenas comunidades agrícolas, que circundam a estrada RS 444, sendo que ali estão localizadas algumas das maiores e mais bem-conceituadas empresas produtoras de bebidas derivadas da uva, do país".

O Vale representa o legado histórico, cultural e gastronômico deixado pelos imigrantes italianos que chegaram à região em 1875. Conforme Zanini e Rocha (2010), esses imigrantes introduziram a vitivinicultura e até hoje, esta se constitui como base da economia das famílias moradoras da região. No Vale dos Vinhedos há aproximadamente 3.000 habitantes, os quais em sua maior parte trabalham no cultivo da vinha. O resultado desta produção resulta em vinhos produzidos em propriedades familiares ou comercializados em cooperativas ou vinícolas da região. Segundo Polita (2006), a estrutura produtiva do Vale é composta por pequenas propriedades rurais que compartilham o território com vinícolas de diferentes portes. Estas vinícolas constituem-se de cantinas familiares, boutiques e de garagem, assim como grandes empresas que contam com parcerias internacionais. 
Conforme Valduga (2012), pode-se dizer que o enoturismo no Vale dos Vinhedos teve algumas fases com características distintas, ainda que muitas coexistam e essas fases foram assim descritas:

1. Fase embrionária (1930 - 1970): período de exposições agroindustriais; pequenas feiras locais e realização da $1^{\circ}$ Festa da Uva, em Caxias do Sul e da Festa Nacional do Vinho - Fenavinho, em Bento Gonçalves;

2. Fase de crescimento (1970 - 1995): período de exposições agroindustriais e festas regionais (Festa da Uva, Fenavinho e Festa Nacional do Champanha - Fenachamp, em Garibaldi); organização de jantares típicos nas cantinas familiares com visitação; criação da Associação de Produtores de Vinhos Finos do Vale dos Vinhedos (APROVALE) com preocupações turísticas;

3. Fase de consolidação (1995 - 20...): período de festas regionais; estruturação das vinícolas para atendimento; calendário de eventos; capacitação profissional; desenvolvimento de certificações e identificação de produtos típicos das regiões vinícolas; criação de novas associações de produtores; preocupação ambiental; primeiros estudos e pesquisas na área do turismo do vinho.

Cabe destacar a classificação proposta por Tonietto (2003) sobre as fases de desenvolvimento da vitivinicultura e do enoturismo na Serra Gaúcha conforme Quadro 1.

Quadro 1: Fases da vitivinicultura e do enoturismo na Serra Gaúcha

\begin{tabular}{|c|c|c|c|c|}
\hline Período & $1^{\text {a }}$ Fase & $2^{\text {a Fase }}$ & $3^{\text {a Fase }}$ & $4^{\text {a Fase }}$ \\
\hline $\begin{array}{c}\text { Geração de } \\
\text { vinhos }\end{array}$ & $1^{\text {a }}$ geração & $2^{\text {a }}$ geração & $3^{\text {a }}$ geração & $4^{\text {a }}$ geração \\
\hline $\begin{array}{c}\text { Estágio da } \\
\text { vitivinicultura }\end{array}$ & $\begin{array}{c}\text { Implantação } \\
\text { Visitar vinhedos }\end{array}$ & $\begin{array}{c}\text { Diversificação de } \\
\text { produtos } \\
\text { Exposições }\end{array}$ & $\begin{array}{c}\text { Incremento da } \\
\text { qualidade e } \\
\text { especialização } \\
\text { Visita a vinícolas }\end{array}$ & $\begin{array}{c}\text { Identidade para o } \\
\text { vinho brasileiro } \\
\text { Associações e roteiro }\end{array}$ \\
\hline $\begin{array}{c}\text { Características } \\
\text { do enoturismo }\end{array}$ & $\begin{array}{c}\text { E cantinas } \\
\text { familiares } \\
\text { na época da } \\
\text { vindima }\end{array}$ & $\begin{array}{c}\text { Agroindustriais } \\
\text { Festas } \\
\text { enogastronômicas }\end{array}$ & $\begin{array}{c}\text { Em áreas urbanas } \\
\text { Degustação de } \\
\text { vinhos }\end{array}$ & $\begin{array}{c}\text { Integrado do vinho } \\
\text { Visita a vinícolas } \\
\text { comerciais } \\
\text { Hospedagem e } \\
\text { gastronomia no } \\
\text { meio rural }\end{array}$ \\
\hline
\end{tabular}

Fonte: baseado em Tonietto (2003).

Na década de 1990, o Setor Vitivinícola apresentou crescimento acelerado, em razão da excelente qualidade dos produtos ofertados, gerando impostos e 
empregos diretos e indiretos, contribuindo de forma significativa na economia da região da Serra Gaúcha e como consequência desse crescimento, as relações mercantis, tornaram-se mais competitivas e complexas. Além disso, o enoturismo da Região do Vale dos Vinhedos existe há mais de 130 anos, acompanhando a evolução da própria vitivinicultura. A identidade cultural fica evidente na diversidade dos produtos (geleias, compotas, biscoitos, conservas, entre outros), cuja comercialização acontece nos varejos das vinícolas, em armazéns ou em lojas especializadas no Vale e nas cidades da região. Outro destaque, diz respeito à qualidade destes produtos, à possibilidade de colheita de alimentos ("comer uva no pé"), entre outros atrativos singulares do Vale (Dalcin,2008).

No contexto brasileiro, o Plano Nacional de Turismo 2013-2016 consolida a Política Nacional de Turismo e apresenta as orientações estratégicas para o desenvolvimento da atividade no Brasil para os próximos anos. Resulta do esforço integrado do governo federal, envolvendo a iniciativa privada e o terceiro setor, por meio do Conselho Nacional de Turismo, sob a coordenação do Ministério do Turismo.

O Plano define as diretrizes que devem nortear o desenvolvimento do turismo brasileiro, como a participação e diálogo com a sociedade; a geração de oportunidades de emprego e empreendedorismo; o incentivo à inovação e ao conhecimento; e a regionalização como abordagem territorial e institucional para o planejamento. Entre as ações previstas no Plano, duas podem ser destacadas por estarem diretamente vinculadas a este estudo: "o conhecimento do turista, do mercado e do território" e "o estímulo ao desenvolvimento sustentável".

Para o World Travel \& Tourism Council (WTTC), no ano de 2015, o setor Viagens e Turismo contribuíram com um total de US\$7,2 trilhões para o PIB mundial, representando 9,8\% do PIB total, cerca de 2,5 milhões de novos empregos diretos foram gerados pelo turismo em 2015, aumentando o número de empregos diretos para 108 milhões, no total, 7,2 milhões de novos empregos foram criados como resultados diretos, indiretos ou induzidos pelo setor, além disso, estima-se que para 2026 é esperado manter 370 milhões de empregos em nível mundial, o que equivalerá a 1 em 9 de todos os empregos do mundo (WORLD TRAVEL \& TOURISM COUNCIL, 2016). 
Estima-se ainda que para o ano de 2022 o turismo seja responsável por 3,63 milhões de empregos. Estão incluídas como geradoras de empregos diretos as atividades relacionadas à hotelaria, agências de viagens, companhias aéreas, outros tipos de transportes de passageiros, restaurante e lazer (figura 1).

Figura 1- Mapa do fluxo turístico internacional para o Brasil.

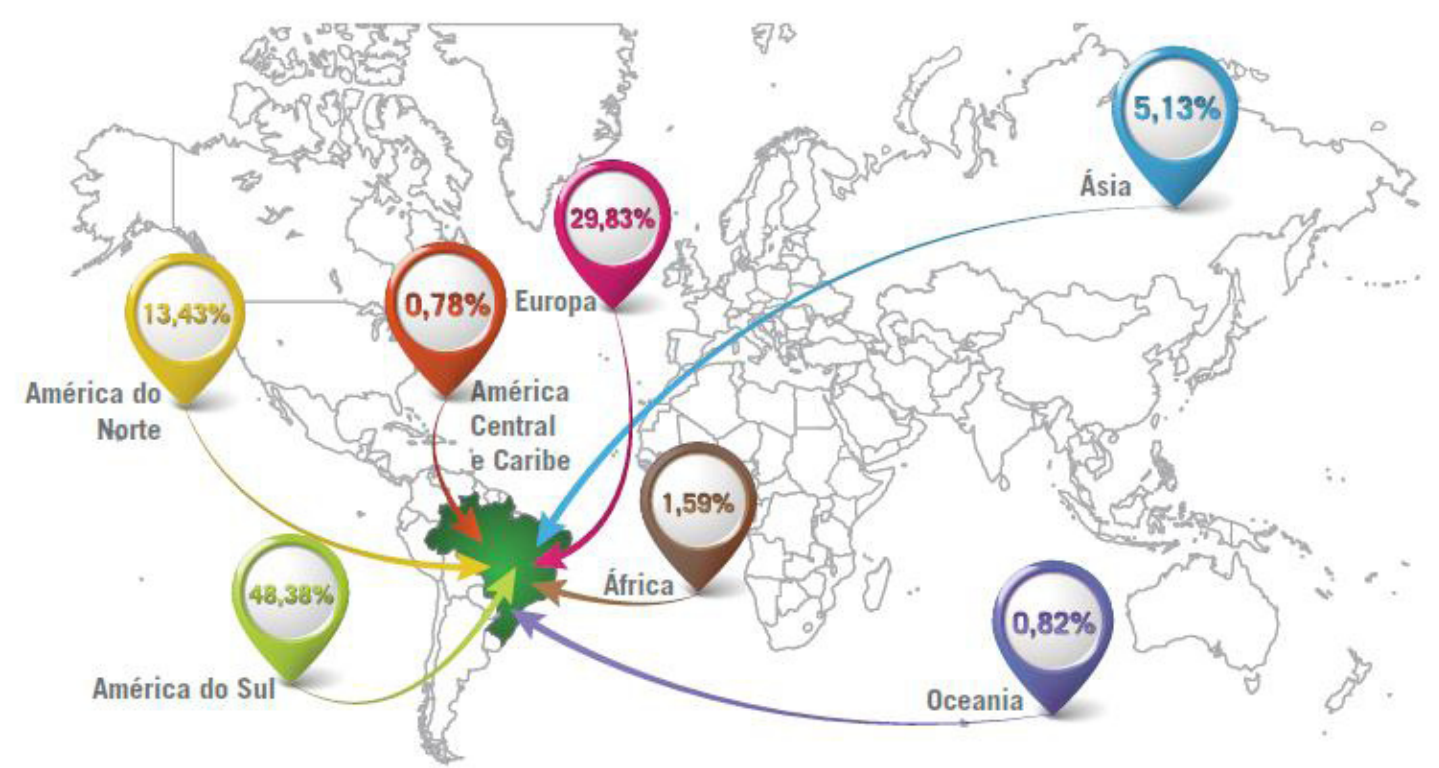

Fonte: Ministério do Turismo (2013).

A participação do turismo na economia brasileira já representa 3,7\% do PIB do país. De 2003 a 2009, o setor cresceu 32,4\%, enquanto a economia brasileira apresentou expansão de 24,6\% (MTUR, 2012). Cabe destacar que o setor do turismo representa $\circ 5^{\circ}$ na Balança de exportações movimentando mais de $\mathrm{R} \$ 7$ bilhões de reais e com as Olímpiadas estima-se que em agosto o Brasil receberá 5 bilhões de pessoas e mais de duzentos países (MTUR, 2014).

No Brasil, a viticultura constitui-se numa atividade agrícola de pequenas propriedades com marcante característica de produção familiar e elevado número de variedades de uvas. Cerca de $65 \%$ desta produção é destinada à elaboração de vinhos, sucos, destilados e outros derivados, enquanto que $35 \%$ destina-se ao consumo in natura. É, atualmente, uma atividade consolidada em 12 regiões produtoras nos estados de Santa Catarina, Paraná, São Paulo, Minas Gerais e ainda com significativo destaque no Vale do São Francisco (Feinsterseifert \& Wilk, 2005).

Acompanhando uma tendência mundial dominante, o segmento de vinhos finos brasileiro vem sofrendo as pressões tanto do processo de globalização dos mercados, quanto da integração econômica no Mercosul. Esse ambiente 
crescentemente competitivo traz por um lado riscos para as regiões vinícolas que não se adaptarem, mas por outro, abre um leque de oportunidades para aquelas que souberem formular estratégias na reconfiguração das atividades da cadeia de valor e no desenvolvimento das capacidades gerenciais e competências coletivas.

As regiões vitivinícolas dependem, de modo geral, diretamente do homem que exerce atividades ligadas à natureza ecológica e, pela tipicidade de produtos que geram, e dando continuidade às tradições seculares, ou seja, transformação do solo para o cultivo da videira e a elaboração do vinho.

Essas regiões e atividades, além de proporcionarem ao homem um estilo de vida, transformaram suas experiências em fontes de conhecimento, tradição, identidade - em cultura. Uma dessas experiências encontra-se na Serra Gaúcha (BR), origem da Região do Vale dos Vinhedos (1875), a qual possui uma ligação muito estreita com os processos migratórios, cumplicidade essa considerada a principal responsável pela fixação do homem na terra. A região é a maior produtora de vinhos do país (responsável por mais de $80 \%$ da produção nacional), e possui importante papel irradiador no desenvolvimento de novas regiões vitivinícolas, tanto através da difusão de tecnologia como de ações empreendedoras. Na figura 2 constam os limites geográficos do Vale dos Vinhedos.

Figura 2 - Região da Indicação de Procedência Vale dos Vinhedos

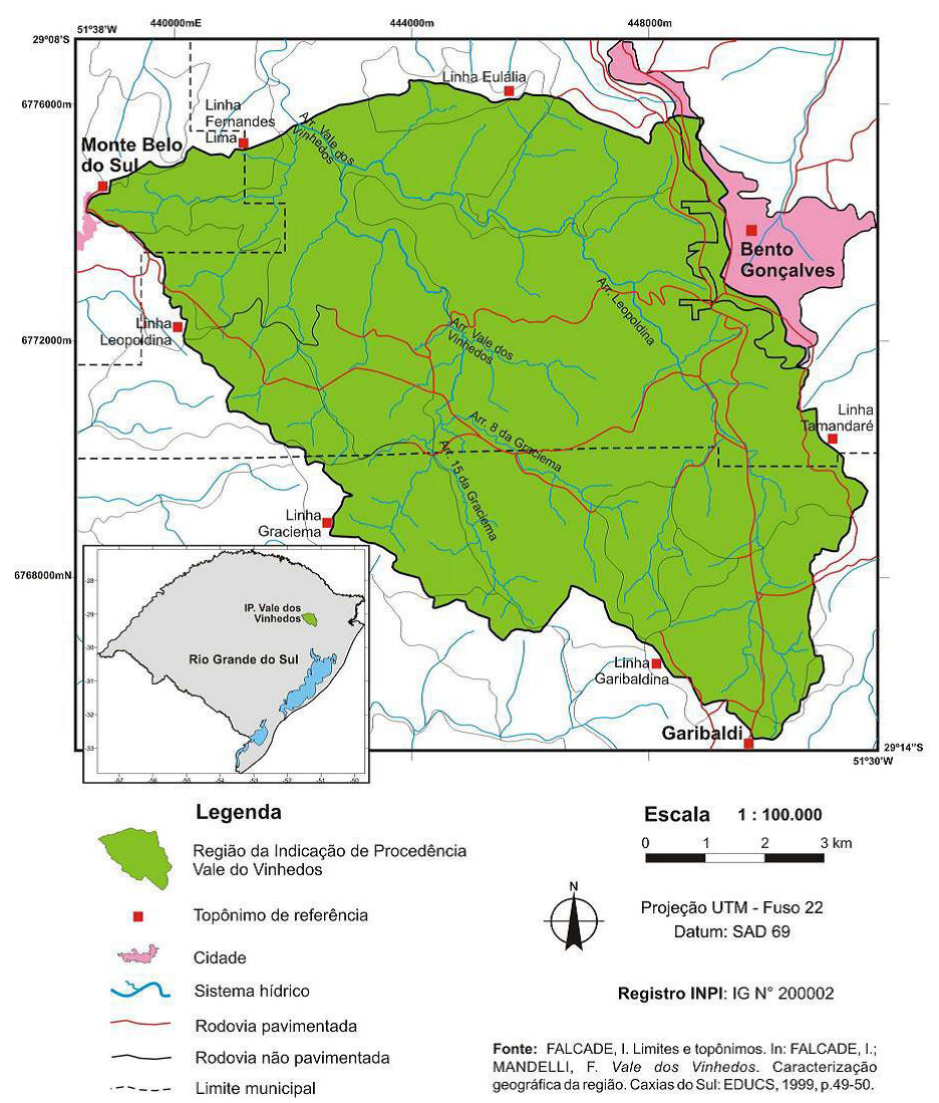


Fonte: Falcade (1999).

O Vale dos Vinhedos foi a primeira região brasileira certificada com a Indicação de Procedência (IPVV) no ano de 2002 e Denominação de Origem (DO) em 2012, tornando-se um dos principais destinos enoturísticos da América e o principal destino de turismo do vinho brasileiro. Cabe destacar que por meio destes processos de certificação regional e da criação de marcas, as regiões se tornam "exclusivas" na produção de determinados produtos e se tornaram turísticas, em função de as pessoas se deslocarem para buscar os produtos na origem.

Em 2015, o Vale dos Vinhedos recebeu mais de 310.000 mil pessoas até outubro (Tabela 1), demonstrando que o enoturismo destaca-se como vital para sustentação de algumas empresas instaladas no Vale, especialmente àquelas em que o produto não é exportável, por exemplo, o caso dos hotéis, pousadas e restaurantes e de uma queijaria existente na rota do turismo (APROVALE${ }^{1}, 2015$ ).

Tabela 1 - Fluxo turístico no Vale dos Vinhedos

\begin{tabular}{c|c|c}
\hline Ano & Fluxo de turistas & \% de crescimento (ano a ano) \\
\hline 2001 & 45.000 & - \\
\hline 2002 & 60.000 & 33,3 \\
\hline 2003 & 82.000 & 36,7 \\
\hline 2004 & 102.000 & 24,4 \\
\hline 2005 & 115.737 & 13,5 \\
\hline 2006 & 105.617 & $-8,7$ \\
\hline 2007 & 120.962 & 14,5 \\
\hline 2008 & 153.779 & 26,7 \\
\hline 2009 & 182.229 & 18,9 \\
\hline 2010 & 200.508 & 10,0 \\
\hline 2011 & 228.579 & 14,0 \\
\hline 2012 & 248.000 & 8,5 \\
\hline 2013 & 283.000 & 14,2 \\
\hline 2014 & 294.966 & $4 \%$ \\
\hline 2015 & $310.000^{\star}$ & $5 \%$ \\
\hline
\end{tabular}

*Levantamento outubro/2015.

Fonte: Aprovale (2015)

1 Associação dos Produtores de Vinhos Finos do Vale dos Vinhedos conta com 26 vinícolas associadas e 43 empreendimentos de apoio ao turismo, entre hotéis, pousadas, restaurantes, artesanatos, queijarias, ateliês de artesanato e antiguidades e outros. A entidade foi fundada em 21 de fevereiro de 1995 e tem como MISSÃO promover o desenvolvimento sustentável do Vale dos Vinhedos através do enoturismo, da integração entre os associados e a comunidade, e para fomentar a busca contínua pela excelência em produtos e serviços. 
Como podemos verificar a partir da análise do ciclo de vida (Figura 3), o Vale dos Vinhedos já passou pelas fases de "Exploração" e "Envolvimento", a qual se caracteriza por poucos turistas descobrindo os aspectos naturais proporcionados pelo espaço e gradativamente o número de turistas aumenta deixando de ser exclusivo dos inovadores e tornando-se legítimo falar de mercado e de época turística dada a dimensão que começa a atingir, respectivamente.

Figura 3 - Curva do ciclo de vida do Vale dos Vinhedos

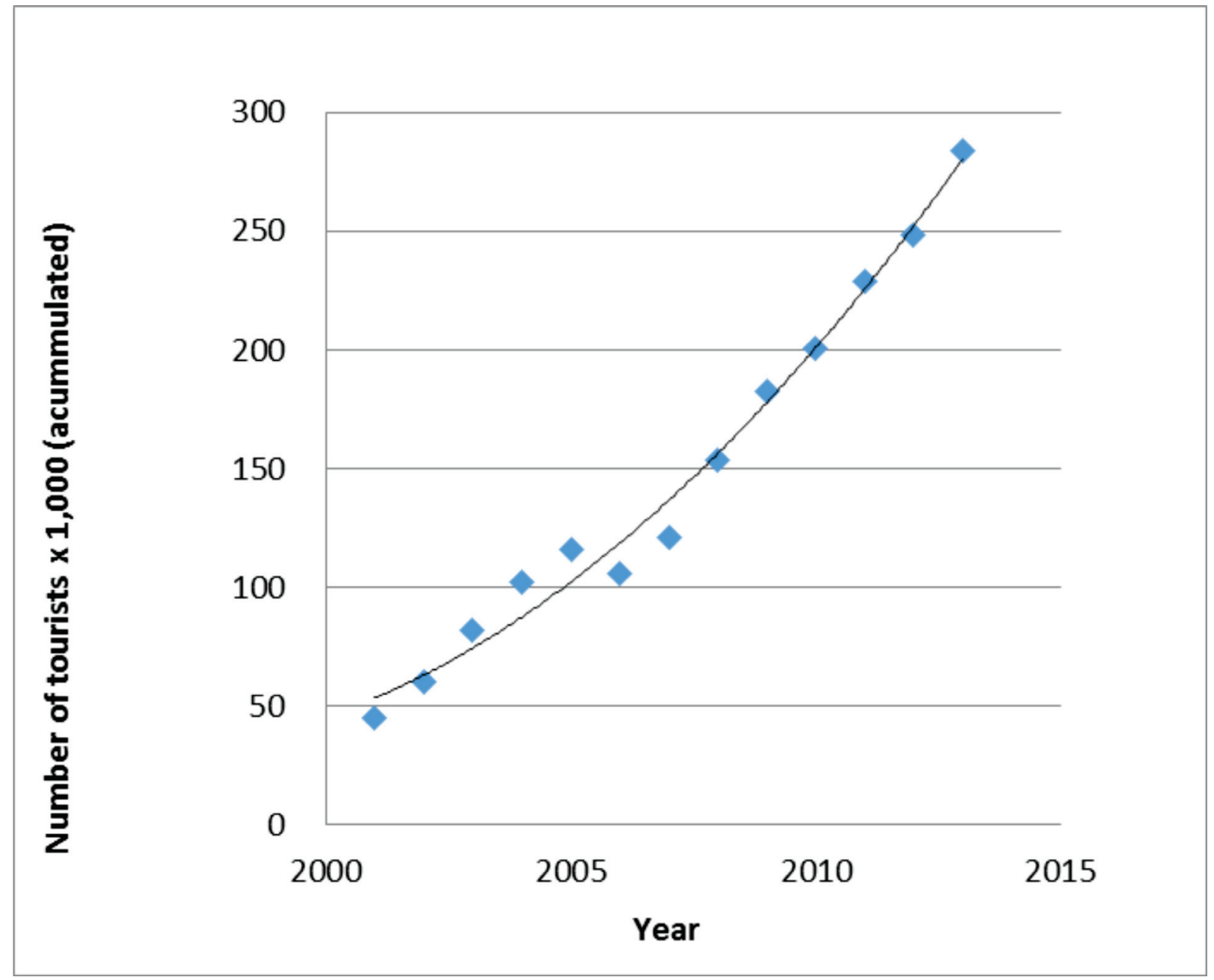

Fonte: Elaborado pelos autores (2016)

Atualmente pode-se afirmar que está no estágio de DDesenvolvimento, ou seja, o número de turistas continua aumentando, embora a taxas menores. É evidente que por se tratar de um roteiro recente (que iniciou no final dos anos 1990) é esperado que o mesmo ainda se encontre em uma fase de expansão (Figura 3). Além disso, na fase de aDesenvolvimento 0 caracteriza-se pelas facilidades turísticas adicionais, fortes campanhas promocionais, nos períodos de maior procura ( no caso específico do Vale o inverno) o número de turistas ultrapassa a população residente. 
Observa-se que nos dois últimos anos há uma estagnação das taxas de crescimento, embora a atividade turística transforma-se numa das principais atividades para economia local, no sentido de geração de empregos e criação de riqueza. Existe um movimento de desenvolvimento de esforços para aumentar a época turística seja na renovação de equipamentos ou na proposta de novos eventos em outras épocas do ano.

Cabe destacar, no entanto que as fases do ciclo não são estanques e sim passíveis de gerar microciclos (Cooper et al., 2001, p.88). A literatura aponta alguns elementos como variações climáticas, reportagens especialmente favoráveis à região, um grande evento, entre outros, e afirmam que "podem ocorrer pequenos decréscimos no fluxo de visitantes ainda na fase de crescimento, ou pequenas elevações na fase de maturidade ou de declínio da localidade".

No caso do Vale dos Vinhedos nos meses de junho, julho e agosto pelas condições climáticas - período de inverno, o fluxo de turistas/visitantes em 2014 foi de 80 mil pessoas e em julho de 2015, de 52 mil pessoas, que desfrutaram de programações especiais para estação mais fria do ano entre elas a celebração da cultura italiana, as degustações e as visitas às vinícolas que fazem parte do roteiro foram alguns doas atrativos. Dialogando com o crescente consumo de espumantes brasileiros, o verão do Vale dos Vinhedos entre os meses de janeiro, fevereiro e março, quando a Vindima ainda está no auge, foram contabilizados 79.629 visitantes de todas as partes, que se renderam ao charme do roteiro (APROVALE, 2015).

No contexto territorial do Vale dos Vinhedos podem ser observadas verticalidades e territorialidades. As verticalidades se dão no conjunto de relações (exógenas), cuja origem é externa ao território, estas relações são concebidas por agentes públicos e/ou privados localizados em outros territórios, em outros níveis escalares, que procuram se apoderar e usar novos espaços. Considera-se que estas relações econômicas, políticas, sociais e culturais, que se estabelecem entre lugares e entre regiões, alcançam um espaço mundializado de relações (Mattia, 2013). 
As horizontalidades, por sua vez, se dão no conjunto de relações (endógenas), cuja origem está no próprio território, onde estas relações são concebidas por agentes públicos e/ou privados localizados no local ou no espaço adjacente, próximo. As relações econômicas, políticas, sociais e culturais se estabelecem nas escalas locais e regionais, nas quais é possível convergir solidariedades locais (Azaïs, 2004).

Por outro lado, também poderíamos analisar o fluxo turístico como um remembramento espacial, porque deriva de uma política institucional, visando a impor outra racionalidade ao seu espaço de atuação que, através da integração destas empresas e da criação de núcleos locacionais os clusters, originou outra organização espacial.

Uma das dificuldades de se utilizar o TALC para análise do ciclo turístico é a falta de dados referentes à dinâmica que envolve o turismo de determinado território. Esta falta de dados é decorrente dos problemas enfrentados pelos planejadores e gestores locais, tais como a escassez de recursos humanos, tecnológicos e financeiros; infraestrutura inadequada, inexistência de legislação ambiental e falta de monitoramento de indicadores.

Uma análise sistêmica do destino, se faz relevante, pois o potencial de atração turística não é infinito e deve ser tratado como finito e utilizador de recursos não renováveis. Dessa forma, os destinos podem ser cuidadosamente protegidos e preservados (Butler, 2006).

Embora o modelo TALC esteja alicerçado neste argumento, cabe destacar algumas limitações. Uma delas diz respeito à dificuldade de se estabelecer fronteiras claras entre as fases, ou seja, nem sempre conseguimos analisar um destino de forma tão linear (Agarwal, 1997; Falcão, Gómez, 2012, Freitas et al., 2014).

Neste sentido, cabe estabelecer indicadores que possam ser monitorados com o objetivo de promover o desenvolvimento sustentável da região. Para tanto, propomos neste estudo o intercruzamento entre os recursos territoriais existentes e as dimensões de desempenho competitivo (Quadro 2). 
Quadro 2 - Proposta de Indicadores para o Vale dos Vinhedos

\begin{tabular}{|c|c|c|}
\hline $\begin{array}{l}\text { Dimensão de desempenho } \\
\quad \text { competitivo } \\
\text { (adaptado de Macke et al., 2013) }\end{array}$ & $\begin{array}{c}\text { Recursos territoriais disponíveis } \\
\text { (adaptado de Fernsterseifert e Wilk, } \\
\text { 2005) }\end{array}$ & $\begin{array}{c}\text { Proposta de Indicadores para Ciclo de } \\
\text { Vida do Destino Turístico "Vale dos } \\
\text { Vinhedos" }\end{array}$ \\
\hline $\begin{array}{c}\begin{array}{c}\text { Apropriação de recursos } \\
\text { endógenos }\end{array} \\
\text { Promoção da identidade } \\
\underline{\text { coletiva }}\end{array}$ & $\begin{array}{c}\text { Relevo (facilidade de plantio e } \\
\text { tratamento) } \\
\text { Insolação } \\
\text { Altitude (geografia de montanha) } \\
\text { Terroir } \\
\text { Localização turística (próximo à } \\
\text { região das Hortênsias) }\end{array}$ & $\begin{array}{l}\text { Definição da capacidade de receber } \\
\text { turistas, sem comprometer o meio } \\
\text { ambiente } \\
\text { Envolvimento da comunidade local nas } \\
\text { decisões de políticas de turismo } \\
\text { Geração de emprego e oportunidades, } \\
\text { com especial atenção à permanência } \\
\text { dos jovens na região. }\end{array}$ \\
\hline $\begin{array}{c}\text { Networking } \\
\text { Troca de informações técnicas } \\
\end{array}$ & $\begin{array}{c}\text { Abertura para estudos e } \\
\text { pesquisas, em especial centros de } \\
\text { pesquisa e escolas técnicas } \\
\text { Criação da APROVALE (Associação } \\
\text { dos Produtores do Vale dos } \\
\text { Vinhedos) }\end{array}$ & $\begin{array}{l}\text { Articulação dos atores para a } \\
\text { coordenação de iniciativas, como } \\
\text { eventos e campanhas promocionais } \\
\text { Credibilidade das instituições e } \\
\text { organizações envolvidas } \\
\text { Parcerias com outras regiões para } \\
\text { intercâmbio, cooperação e projetos. }\end{array}$ \\
\hline $\begin{array}{c}\text { Ativos organizacionais } \\
\text { Melhores práticas de gestão }\end{array}$ & $\begin{array}{l}\text { Processo diferenciado na produção } \\
\text { de uvas e vinhos } \\
\text { Vinícolas com vinhedos próprios } \\
\text { (especialização de parreirais) }\end{array}$ & $\begin{array}{l}\text { Estratégias integradas de } \\
\text { competitividade estabelecidas entre } \\
\text { diferentes atores } \\
\text { Programas de qualificação profissional } \\
\text { e capacitação de empreendedores } \\
\text { Criação de novos produtos e serviços } \\
\text { turísticos. }\end{array}$ \\
\hline
\end{tabular}

Fonte: Elaborado pelos autores (2016).

Utilizando-se das dimensões apontadas por Macke et al. (2013), vinculamos às mesmas aos recursos territoriais disponíveis do Vale apontados por Fernsterseifert e Wilk (2005). O estudo proposto por Fernsterseifert e Wilk (2005), promoveu uma conversação entre a abordagem conhecida como Visão da Firma Baseada em Recursos (VBR) e o estudo de clusters industriais, visando a análise de seus recursos estratégicos (Quadro 2). Desta vinculação, apontamos indicadores de monitoramento do ciclo de vida para o caso do Vale dos Vinhedos.

O estudo de Fernsterseifert e Wilk (2005) propôs uma nova tipologia para a classificação de recursos estratégicos em clusters, baseada em três conceitos: recursos singulares, recursos sistêmicos (este não foi objeto do 
estudo) e recursos de acesso restrito. A seguir apresenta-se um breve resumo destes recursos.

Os recursos singulares são os que pertencem às firmas individuais. São sustentados estrategicamente pela trajetória tecnológica individual da firma, história familiar, contratos de longo prazo, co-especialização de ativos. Os recursos singulares induzem a diferenças de performance entre as firmas e, quando percebidos pelos gestores e explorados competitivamente, permitem a aquisição e defesa de posições de vantagem no mercado. No estudo foram identificados os seguintes recursos como singulares: relevo; terroir; processo diferenciado na produção de uvas e vinhos e vinícolas com vinhedos próprios.

Os recursos de acesso restrito não pertencem a nenhuma firma individual mas podem ser acessados de maneira privilegiada por um subconjunto determinado de firmas do cluster, os recursos restritos beneficiam firmas que adotam determinadas condutas no ambiente em que participam. O acesso restrito se dá em função de múltiplos fatores, entre eles, a iniciativa das firmas de acessá-los, sua condição prévia em termos de recursos e conhecimentos complementares, vantagens de posicionamento geográfico, sua participação na história da formação do aglomerado de firmas e seu capital de relacionamentos estratégicos. Induzem a formação de grupos estratégicos de firmas diferenciadas de alta performance dentro de uma indústria. Neste estudo foram os seguintes recursos restrito: localização turística; altitude; Insolação; abertura para estudos e pesquisas; criação da APROVALE.

Cada categoria de recursos contribui de uma forma distinta na construção de vantagens competitivas. Os recursos singulares propiciam a diferenciação e a competição entre as firmas do cluster, mas influenciam, em certo grau, as barreiras à entrada na indústria como um todo. Os recursos restritos atuam como uma variação dos sistêmicos influenciando a competitividade sistêmica e as barreiras do cluster a partir da indução diferenciada da competitividade em grupos estratégicos de firmas.

A I Conferência Municipal de Planejamento Territorial de Bento Gonçalves aconteceu em maio de 2012 e gerou um documento de compromissos, o qual prevê a fiscalização do avanço urbano ilegal sobre a zona de proteção de 
paisagem do Vale dos Vinhedos. Este plano diretor poderá ser um caminho para a preservação da paisagem local, através de diretrizes que limitem a construção e urbanização desordenada.

Para que este o ciclo de vida do destino possa ser prolongado é fundamental a participação da comunidade em conjunto com órgãos competentes e empresários locais, a fim de que as políticas sejam representativas dos interesses de diferentes atores. Dessa forma, o desenvolvimento territorial, passa a estar vinculado a um processo localizado de desenvolvimento no território, envolvendo as dimensões sociais, humanas, econômicas, físico-naturais, ambientais, políticas e culturais do território (Dallabrida \& Fernández, 2008)

Assim sendo, propomos que este conjunto de indicadores sejam monitorados para que o território possa se desenvolver com sustentabilidade, fortalecendo o enoturismo e outras atividades fundamentais para a construção da identidade e marca regional - Vale dos Vinhedos.

\section{CONSIDERAÇÕES FINAIS}

O conceito de território constitui o traço de união entre o passado e o futuro imediato. Neste sentido, a territorialização do Vale dos Vinhedos, conforme foi planejado sob uma perspectiva integradora, articulada em múltiplas escalas, local/comunitária/territorial/global, possibilitando sua superposição e sua descontinuidade espacial, mesmo que conectadas e articuladas entre si.

Desde 2001, quando a Aprovale iniciou a contabilização da evolução do fluxo turístico no Vale dos Vinhedos, esse número cresceu 6,5 vezes em 13 anos, traduzindo positivamente o reconhecimento dos vinhos e espumantes brasileiros e consolidando o Vale dos Vinhedos como um dos principais roteiros enoturísticos do Brasil, o qual reúne paisagens bucólicas, gastronomia acolhedora e vinhos de excelente qualidade.

Como um dos resultados, teve-se a identificação de que o Vale está na fase de Desenvolvimento do seu ciclo de vida. Além disso, esta análise permite inferir que a marca regional e o enoturismo contribuíram para o fortalecimento do destino Vale dos Vinhedos. 
Acredita-se que o aumento do número de visitantes deu-se por alguns fatores específicos, tais como: Valorização territorial obtida a partir da obtenção da Indicação de Procedência Vale dos Vinhedos e Denominação de Origem Vale dos Vinhedos; Crescente investimento na qualificação da produção do Vale dos Vinhedos (desde o pequeno produtor até as grandes empresas); Elaboração de plano de marketing para melhor gestão da "marca" Vale dos Vinhedos; Investimento em marketing e divulgação do roteiro e produtos mídia espontânea e marketing de cada empreendimento; Participação em feiras e eventos destinados ao turismo e ao vinho; Incentivos que propiciaram o turismo no território nacional, divulgação dos destinos brasileiros no exterior e participação em ações da Secretaria de Turismo de Bento Gonçalves na divulgação das rotas locais.

Os recursos identificados como vantagem de altitude, vantagem de insolação, vantagem de relevo, vantagem de terroir (considerado como as condições edafoclimáticas do local produtivo), experimentos com variedades viníferas (aqui considerado como a capacidade de realizar estes experimentos) e vinhedos próprios revelam a importância do papel desempenhado pela produção das uvas como precursor de vantagem competitiva na produção de vinhos. Entre os quatro primeiros recursos, expressam-se os atributos de imobilidade, inimitabilidade e escassez, pois não são todas as terras disponíveis na região que apresentam condições favoráveis. Por sua vez, os recursos definidos como processo diferenciado na produção de vinhos ou uvas (também considerado como uma capacitação ou recurso de conhecimento) e acesso a centros de pesquisa (o centro de pesquisa é o recurso) relacionam-se à produção de vinhos e envolvem a presença de dependências de caminho, investimentos e conhecimentos não mapeados entre outros atributos de sustentação estratégica.

Os indicadores propostos objetivam que o Vale se desenvolva com sustentabilidade, isto é, o fortalecimento endógeno com a capacidade para o desenvolvimento econômico do local (Profit), o tratamento e o desenvolvimento do capital humano (People) e a preservação do capital natural (Planet) a compatibilidade entre a atividade do enoturismo e a proteção dos ecossistemas. 
Com certeza o assunto ainda não foi esgotado, e novas abordagens sobre destino e o modelo aqui apresentado poderão contribuir para a construção do conhecimento científico baseado em dados e estudos que auxiliem o desenvolvimento do tema.

\section{REFERÊNCIAS}

Agarwal, S. (1997). The resort cycle and seaside tourism: an assessments its applicability and validity. Tourism Management, 18(2), 65-73.

Azaïs, C. (2004). Território e trabalho: uma inscrição em temporalidades diferentes. Novos Cadernos NAEA, 7(1), 31-56.

Brasil. Presidência da República. Ministério do Turismo. (2013). Plano Nacional de Turismo. MT, Brasília.

Butler, R. W. (1980). The concept of Tourist Area Cycle of Evolution: Implications for Management of Resources. The Canadian Geographer, 24, 512.

. (2006). The Origins of the Tourism Area Life Cycle. In R. W. Butler (Ed.), The Tourism Area Life Cycle (pp. 13-26). Clevedon, Inglaterra: Channelview Publications.

Choy, D. J. L. (1992). Life Cycle Models for Pacific Island Destinations. Journal of Travel Research, 30(3), 26-31.

Cooper, C., Fletcher, J., Fyall, A., \& Gilbert, D. S. (2007). Turismo: princípios e práticas. Porto Alegre, RS: Bookman.

Copello, M., \& Queiroz, S. (2014). Anuário Vinhos do Brasil. Ibravin: BACO.

Dalcin, M. S. (2008). Vale dos Vinhedos: história, vinho e vida. Bento Gonçalves, RS: Gráfica Palotti.

Di Méo, G. (1998). Géographie sociale et territoire. Paris, França: Éditions Nathan.

Falcade, I. (2001). O espaço geográfico e o turismo na Região da Uva e do Vinho no nordeste do Rio Grande do Sul. In Encontro Estadual de Geografia (p. 21). Caxias do Sul, RS: Educs.

Falcão, M. C.; Gómez, C. R. P. (2012). Análise da Sustentabilidade de Destinos Turísticos: uma proposta teórica de adequação do modelo de ciclo de vida de áreas turísticas às dimensões da sustentabilidade. Turismo: Visão e Ação, 14 (3), 304-321.

Faria, D. S. de, \& Carneiro, K. S. (2001). Sustentabilidade Ecológica no Turismo. Brasília, DF: Editora Universidade de Brasília. 
Fensterseifer, J. E., \& Wilk, E. O. (2005). Visão da firma baseada em recursos, clusters e performance: um estudo no setor vitivinícola do RS. In Encontro da Associação Nacional de Pós-graduação e Pesquisa em Administração (p. 29). Brasília, DF: Anpad.

Fischer, T. (2002). Poderes Locais, Desenvolvimento e Gestão. Introdução a uma agenda. In: T. Ficher, (Ed.), Gestão do Desenvolvimento e Poderes Locais: marcos teóricos e avaliação (pp. 12-32). Salvador, BA: Casa da Qualidade.

Freitas, N. R., Souza, P. A., Zambra, E. M., Pereira, R. D., e Romeiro, M. D. (2014). As discussões sobre sustentabilidade na atividade turística: uma análise para o Brasil na última década. El Periplo Sustentable, 54-91, n. 27.

Gumuchian, H., \& Pecqueur, B. (2007). La ressource territoriale. Paris, França: Anthropos.

Haywood, K. M. (2006). Evolution of the Tourism Areas and the Tourism Industry. In R. W. Butler (Ed.), The Tourism Area Life Cycle (pp. 51-70). Clevedon, Inglaterra: Channelview Publications. Kotler, P., \& Keller, K. (2006). Administração de marketing. São Paulo, SP: Pearson Prentice.

Lagiewski, R. M. (2006). The Application of the TALC Model: a literature survey. In R. W. Butler (Ed.), The Tourism Area Life Cycle (pp. 27-50). Clevedon, Inglaterra: Channelview Publications.

Lakatos, E. M., Marconi, M. de A. (2011). Metodologia Científica. São Paulo, SP: Atlas.

Macke, J., Vallejos, R. V., Faccin, K., \& Genari, D. (2013). Social Capital in Collaborative Networks Competitiveness: the case of the Brazilian Wine Industry Cluster. International Journal of Computer Integrated Manufacturing, 26(1-2), 117-124.

Mollard, A. (2001). Qualite et developpement territorial : une grille d'analyse theorique a partir de la rente. Economie rurale, (263), 16-34.

Raffestin, C. (1993). Por uma geografia do poder. São Paulo, SP: Ática.

Ruschmann, D. (1997). Turismo e Planejamento Sustentável: a proteção ao meio ambiente. Campinas, SP: Papirus.

Santos, M. (1988). Metamorfases do espaço habitado. São Paulo, SP: HUCITEC. . (1999). Por uma geografia nova. São Paulo, SP: Hucitec. (2002). Espaço e sociedade. Petrópolis, RJ: Vozes. 

. (2012). A natureza do espaço: técnica e tempo, razão e emoção. São Paulo, SP: Edusp.

Saquet, M. A. (2009). Por uma abordagem territorial. In M. A. Saquet, E. S. Sposito (Org), Territórios e territorialidades: teorias, processos e conflitos (pp. 73-94). São Paulo, SP: Expressão Popular.

Sarate, J. A. R. (2014). O "Habitante" sob a Perspectiva da Economia do Território. Tese de Doutorado. Universidade Federal do Rio Grande do Sul, Porto Alegre.

Souza, M. J. L. (2006). O território: sobre espaço e poder, autonomia e desenvolvimento. In I. E. Castro, P. C. C. Gomes, \& R. L. Correa (Org.) Geografia: conceitos e temas (pp. 77-116). Rio de Janeiro, RJ: Bertrand Brasil.

Tonietto, J. (2003). Indicações Geográficas para Vinhos Brasileiros. Disponível em: sistemasdeproducao.cnptia.embrapa.br/FontesHTML/Uva/ UvasViniferasRegioesClimaTemperado/indicacoes.htm

Urry, J. (1999). O Olhar do Turista: Lazer e Viagens nas Sociedades Contemporâneas. São Paulo, SP: Studio Nobel.

Valduga, V. (2012). O Desenvolvimento do enoturismo no Vale dos Vinhedos (RS/BRASIL). CULTUR - Revista de Cultura e Turismo, 6(2), 127-143.

Word travel \& tourism council. (2016). Travel \& Tourism Economic Impact 2016 Annual UPDate Summary. Trad. Observatório de Turismo do Rio Grande do Sul.

Zanini, T. V., \& Rocha, J. M. da. (2010). O Enoturismo no Brasil: um estudo comparativo entre as regiões vinícolas do Vale dos Vinhedos (RS) e do Vale do São Francisco (BA/PE). Turismo Em Análise, 21(1), 68-88.

\section{Contribuição dos autores na construção do artigo:} Mattia - referencial teórico, análise de dados, revisão final. Macke - referencial teórico, análise de dados, formatação. Sarate - referencial teórico, análise de dados. 